\title{
Experimental evaluation of galvanic oxidation rates of sphalerite and galena dissolution in seawater \\ SHIGESHI FUCHIDA
}

Waseda University

Presenting Author: sfuchida@aoni.waseda.jp

Sulfide mineral dissolution is an important reaction that controls geochemical and environmental chemical processes in aqueous environments, and is related to processes for metalliferous deposit formation, acid mine drainage generation, and toxic metal release from tailings and other industrial waste. Although the mechanisms and kinetics of individual major sulfide mineral (e.g., pyrite, sphalerite, and galena) oxidation have been extensively investigated in low ionic strength and acidic solutions, galvanic interactions caused by a direct contact of different sulfide minerals is estimated to accelerate greatly metal dissolution from sulfides. Pyrite and chalcopyrite have relatively higher resting potential than sphalerite and galena, resulting in the selective dissolution of $\mathrm{Zn}$ and $\mathrm{Pb}$, when they come into contact with pyrite. In this study, we quantitatively evaluated the galvanic effect on sphelerite and galena dissolutions in seawater. Four hydrothermal sulfides with different amounts of $\mathrm{Fe}$ (galvanic coupling) were reacted in artificial seawater for $144 \mathrm{~h}$, and the dissolution rates of $\mathrm{Zn}$ and $\mathrm{Pb}$ were determined by the EDTA extraction method. The dissolution rates of $\mathrm{Zn}$ were about 10 times higher than low $\mathrm{Fe} / \mathrm{Zn}$ molar ratio samples $(<0.002)$, and that of $\mathrm{Pb}$ from a sample with high $\mathrm{Fe}$ were about nine times higher than a reference data of single galena dissolution rate. More soluble $\mathrm{PbSO}_{4}$ could explain the intense release of $\mathrm{Pb}$ from other samples. These results and mineralogical observations with $\mathrm{X}$ ray diffraction, X-ray photoelectron spectroscopy, and electron probe micro-analysis of sulfide mineral particulates provide evidence for the selective dissolution of anodic sulfide minerals (e.g., sphalerite and galena) at a higher reaction rate than cathodic sulfide minerals. 